\title{
Biopoder e Práticas Reguladoras do Uso de Drogas no Brasil: Algumas Análises de Projetos de Lei
}

\author{
Biopower and Regulatory Practices of Drug Use in Brazil: \\ Some Analyzes of Bills \\ Prácticas de Biopoder Y Regulatorio del Uso de Drogas en Brasil: \\ Algunos Análisis de Proyectos de Ley
}

\section{Artur Barbedo do Nascimento Couto}

Universidade Federal do Pará, Belém, PA, Brasil

Flávia Cristina Silveira Lemos

Universidade Federal do Pará, Belém, PA, Brasil

Mariane Batista Bittencourt Couto

Universidade Federal do Pará, Belém, PA, Brasil

\begin{abstract}
Resumo
O presente artigo visa analisar a prática do biopoder acionada pela internação compulsória de usuários de drogas e pelas propostas de projeto de lei referentes a essa maneira de governar os corpos e segmentos da população. Pensar o dispositivo de segurança articuladamente à medicalização e à criminalização na política sobre drogas é relevante na atualidade, sobretudo em tempos em que a internação passa a ser usada indiscriminadamente em defesa da sociedade e para disciplinar os corpos indóceis à lógica empresarial da vida e à mercantilização da saúde. Operar a crítica à medicalização e à judicialização do cotidiano no plano do uso de substâncias legais e ilegais implica em trazer para o campo analítico um analisador acerca da política de subjetivação no tempo presente em que vivemos.
\end{abstract}

Palavras-chave: Biopoder; Política sobre drogas; Racismo.

\section{Abstract}

This article aims to analyse the practice of biopower thrown by compulsory hospitalization of drug users and the project proposals of law pertaining to this way of govenring bodies and segments of the population. Wonder articulately security device the medicalization and criminalization in politics about drugs is relevant today, especually in times whn the hospitalization is used indiscriminately in defense of society and to discipline the waywar bodies to business logic of life and the commodification of health. Operate the critique of medicadicalization and the legals of everyday life in terms of the use of legal and ilegal substancies implies bringing to the 
analytical field a parser about the politics of subjectivation in the present tense in which we live. Keywords: Biopower; Policy and Drugs; Racism.

\section{Resumen}

El presente artículo tiene como objetivo analizar la práctica del biopoder provocada por la hospitalización obligatoria de los consumidores de drogas y el proyecto de ley sobre esta forma de los órganos de gobierno y sectores de la población. Piense dispositivo de seguridad articulada a la medicalización y la criminalización de la política de drogas es relevante hoy en día, sobre todo en momentos en que el hospital es ahora utilizado indiscriminadamente en la defensa de la sociedad y de la disciplina cuerpos rebeldes a la lógica de negocio de la vida y la mercantilización de la la salud. Operar la crítica de la medicalización y judicialización cotidiana en términos de la utilización de sustancias legales e ilegales implica traer al analizador de campo analítico sobre la subjetividad política en el momento actual en el que vivimos.

Palabras clave: Biopoder; Politica de las drogas; Racismo

\section{Introdução}

No presente artigo pretendemos promover problematizações acerca de dois Projetos de lei (PL nº 3.450/12 e PL 4.871/12) que sugerem alterações na Legislação Brasileira sobre Drogas (Lei $\left.n^{0} 11.343 / 06\right)$. Para tal, acionaremos algumas ferramentas analíticas propostas por Michel Foucault, tais como: a construção da "periculosidade" enquanto prática que sustenta a criminalização em um nível das virtualidades dos comportamentos dos corpos que utilizam drogas.

Também temos o objetivo de descrever e interrogar intervenções de saber-poder baseada nas tecnologias disciplinares e biopolíticas, que se atualizam em "novas" práticas de disciplinamento docilizador do corpo-organismo e da regulação do corpo-espécie da população na criminalização e na medicalização das condutas dos usuários de drogas.

Inicialmente, faremos uma descrição de alguns conceitos de Michel Foucault em interface com a política de saúde e de segurança, na assistência tutelar às condutas e que opera no plano criminalizante das mesmas, em um processo de jurisdicionalização da vida que aciona a saúde como regulação medicalizadora de maneira autoritária mais que terapêutica.

Em seguida, apresentaremos uma breve análise documental de projetos de lei 
que serão problematizados historicamente para questionarmos a naturalização de racismos presentes nos mesmos. O objetivo é colocar em xeque as articulações que foram forjadas entre os objetos risco, periculosidade, racismo de Estado e de sociedade securitário, disciplinas docilizadoras das condutas, medicalização da saúde e uso de drogas.

Novos arranjos na arte de lidar com as drogas no Brasil atual, especialmente a partir de 2011, reacenderam velhos debates quanto à gestão da vida dos usuários e usuárias de substâncias legais e ilegais: internação involuntária e compulsória, financiamento de leitos em Comunidades Terapêuticas a partir com financiamento do Sistema Único de Saúde (SUS) entre outros. A prática de internação compulsória, definida legalmente pela Lei $n^{\circ} 10.216 / 2001$, apelidada de Lei Paulo Delgado é alvo de críticas pela maneira como vem sendo aplicada nos grandes centros urbanos do país e também no interior como medida de um processo de medicalização autoritária da indigência.

Apesar da Lei 10.216/2001 ter sido um avanço no campo da Reforma Psiquiátrica brasileira; de um lado, por outro, ela trouxe o dispositivo da internação compulsória como parte de seu texto. No Artigo nono, pressupõe a possibilidade de internação compulsória por requisição do juiz. No caso dos avanços da Lei 10.216/2001 podeRev. Polis e Psique, 2013;3(2):132-150 mos citar a criação dos Centros de Atenção Psicossocial e determinação para fechamento dos leitos em hospitais psiquiátricos, no país.

A internação compulsória que deveria ser uma medida de exceção, de excepcionalidade, no texto da referida lei acabou sendo aplicada de maneira generalizada e é, para muitos usuários de drogas, o primeiro contato com os serviços de saúde. O encontro do campo da saúde com o da segurança traz à tona a capilaridade disciplinar individualizante simultânea aos processos de totalização de governo da vida com o poder pastoral na atualização do dispositivo do biopoder de um racismo de sociedade e de Estado (Foucault, 2005).

$\mathrm{O}$ racimo de Estado e de sociedade é uma prática que coloca em cena mecanismos de poder, saberes, leis e instituições que segregam alguns grupos sociais, que passam a ser desqualificados socialmente e alvo de internação, entre outros dispositivos de retiradas dos mesmos da convivência social em nome da segurança dos que são classificados como ameaçados em função da presença daqueles que são taxados de perigosos ou em risco de sê-lo. O sistema de classificação de risco/perigo traz uma série de preconceitos e racismos, por isto, Foucault (2005) o denominou de biopoder e operou a crítica desse diagrama de práticas securitárias em nome da vida de alguns. 
Práticas medicalizadoras autoritárias e securitárias de internação norteiam os debates acerca destas intervenções, que podem ser encontradas cristalizadas em projetos de leis, matérias cotidianas de jornais impressos e online, planos de enfrentamento do Governo Federal durante o primeiro mandato da Presidente Dilma como o construído para lidar com o crack de forma destacada às outras drogas.

Foucault (1979a) descreveu, em A política de saúde no século XVIII que, para alguns grupos sociais, sobretudo, pobres, passaram a ser administradas práticas de medicalização pautadas no higienismo autoritário enquanto para as classes mais abastadas eram previstas medidas de cunho mais terapêutico, tais como: psicoterapias, por exemplo. Assim, podemos afirmar que, na internação compulsória de usuários de crack é materializada a vertente autoritária da medicalização, ou seja, o higienismo como limpeza urbana e a polícia da ordem entra em cena.

\section{Pensando com Foucault o documento na genealogia}

Esse texto é parte das análises realizadas em pesquisa de mestrado em psicologia, com bolsa CAPES e de iniciação científica com bolsa CNPQ. Nos dois estudos, utiliza-se a genealogia como metodologia e Rev. Polis e Psique, 2013; 3(2):132-150 análise de documentos do legislativo brasileiro a respeito da internação compulsória, após a aprovação do Plano crack: é possível vencer, pela Presidente Dilma Roussef.

Descrever mesmo que brevemente o trabalho de análise de poder-saber usado na perspectiva genealógica é de substancial importância para que o leitor possa entender porque trabalhamos com os conceitos de biopoder, de biopolítica e de disciplina como contribuições de Michel Foucault e a relevâncias das mesmas para as reflexões propostas nesse artigo.

Neste artigo, nos apropriamos de algumas ferramentas de Foucault, como o exercício genealógico da análise de documentos que funcionam como um dispositivo, constituído por leis e normas, resultantes de projetos de lei na esfera Legislativa, de formulação de Programas e planos em políticas nacionais pelo Executivo e na interferência cada vez mais inflacionada do Poder Judiciário nas nossas existências, em especial do que rompe com uma ordem social baseada em racionalidades de tolerância zero em relação aos desvios sociais e às indisciplinas diante das normas de saúde, por exemplo.

Entendemos que todo documento como um monumento, ou seja, um objeto natural. Criticar o que chamamos de documento-monumento implica em pensar a materialidade das práticas de produção do 
mesmo, em um jogo específico de forças é um acontecimento cuja possibilidade de emergência é única, singular. Sendo assim, entendemos os documentos-monumentos como acontecimentos dispostos em um jogo múltiplo, marcado por práticas políticas, econômicas, culturais, sociais e históricas. $\mathrm{Na}$ análise-documental, o genealogista analisa as descontinuidades dos acontecimentos, a produção e as resistências nas lutas que não cessam.

Os documentos não são retratos fiéis de uma suposta realidade e, muitos menos são neutros e imparciais. Eles têm história e resultam de lutas e disputas políticas heterogêneas. Devemos lembrar que "só há constituição de um documento e de seu armazenamento em um arquivo a partir da entrada em cena de práticas de poder sobre os corpos" (Lemos et al, 2010, p. 107). Assim, os Projetos de Leis analisados são, aqui, pensados como documentos produzidos em uma relação de poder específica. Possuem uma história não linear e são efeitos de práticas datadas em um tempo e em um lugar.

Gostaria de mostrar quais são as formas de práticas penais que caracterizam essa sociedade; quais as relações de poder subjacentes a essas práticas penais; quais as formas de saber, os tipos de conhecimento, os tipos de sujeito de conhecimento que emergem, que aparecem a partir e no espaço desta sociedade disciplinar que é a sociedade contemporânea. (Foucault, 2011, p. 79)
Há uma ordem do discurso que é transformada e produzida como efeito de controles sociais, de práticas sociais de poder-saber que se efetuam por meio de leis, de documentos, de textos em jornais, de uma arquitetura, de fotos, de repartições de saberes e de espaços geridos de modo disciplinar. Um documento é um regime de verdade e um efeito de poder, sustenta práticas e é uma prática correlata a outras vizinhas.

Para Foucault (1979b), a genealogia é documentária e cinza porque atua na minúcia da análise histórica sem ideais, por isso, se coloca nos entremeios tateando e deslocando o que parecia evidência, explicitando as vilanias e as batalhas travadas para que um objeto emerja e ganhe visibilidade política.

Descrever mesmo que brevemente o trabalho de análise de poder-saber usado na perspectiva genealógica é de substancial importância para que o leitor possa entender porque trabalhamos com os conceitos de biopoder, de biopolítica e de disciplina como contribuições de Michel Foucault e a relevâncias das mesmas para as reflexões propostas nesse artigo.

A genealogia nos permite desnaturalizar e marcar os acontecimentos que são as condições de possibilidades de emergência e proveniência de um objeto Pol-Droit (2006). É um processo de insurreição de saberes que foram sujeitados e de abertura 
de campos de possibilidades reduzidos pelo controle social disciplinar e biopolítico. Trata-se, de fato, de um de questionamento, de uma postura analítica e ética do pesquisador de estranhamento constante com uma preocupação histórica com os intoleráveis do presente em que vive. Pol-Droit (2006) publica o que Foucault, quando questionado sobre o seu fazer, respondeu:

$\mathrm{Eu}$ sou um pirotécnico. Fabrico alguma coisa que serve, finalmente, para um cerco, uma guerra, uma destruição. Não sou a favor da destruição, mas sou a favor de que se possa passar, de que se possa avançar, de que se possa fazer caírem os muros. Um pirotécnico é, inicialmente, um geólogo. Ele olha as camadas do terreno, as dobras, as falhas. O que é fácil cavar? O que vai resistir? Observa de que maneira as fortalezas estão implantadas. Perscruta os relevos que podem ser utilizados para esconder-se ou lançar-se de assalto. Uma vez tudo isto bem delimitado, resta o experimental, o tatear. (...) O método, finalmente, nada mais é que esta estratégia. (Pol-Droit, 2006, p. 69-70)

A genealogia, para Foucault (1984), é um trabalho de insurreição de saberes:

Trata-se de ativar saberes locais, descontínuos, desqualificados, não legitimados, contra a instância teórica unitária que pretenderia depurá-los, hierarquizá-los, ordená-los em nome de um conhecimento verdadeiro, em nome dos direitos de uma ciência detida por alguns.

(Foucault, 1984, p. 268)

Problematizar consiste em descrever as relações de poder exercidas e materializadas em uma determinada sociedade, implica em pensar que saberes são desqualificados na política sobre drogas quando se decide pela internação compulsória e não pela redução de danos, por exemplo. Ainda podemos destacar que há saberes das humanidades e de movimentos sociais de educação popular em saúde que foram deixados de lado ou, no mínimo, desprezados no lançamento do Plano crack: é possível vencer, pois, a ênfase desse plano foi uma perspectiva biomédica e neurofisiológica em termos de explicação do uso e das conseqüências do uso do crack.

Assim, podemos explicitar ao leitor que a genealogia é uma ferramenta interessante para estudos documentais e para descrevermos e analisarmos relações de saber e de poder, tais como o biopoder na política de internação compulsória, que é a temática desse artigo e das pesquisa em andamentos que realizamos na graduação e na pós-graduação, em psicologia.

\section{Penalidade e disciplina docilizadora}

Foucault situa a reforma do sistema jurídico-penal como um dos elementos que 
possibilitaram a formação da sociedade disciplinar, durante os séculos: XVII e XVIII. Tais transformações perpassam, inicialmente, "por uma reelaboração teórica da lei penal" (Foucault, 1996, p. 80). A primeira reelaboração que pode ser tomada como um princípio fundamental deste sistema teórico apontado pelo autor diz respeito à suposta natureza do crime, deslocando-o de uma visão moralista para a perspectiva positivista do Direito e atualizada na Política Criminal. Na citação, abaixo, podemos visualizar como os juristas passam a pensar o crime por meio do discurso penal delimitado legalmente e só poderia existir nesse âmbito e não apenas por elementos do campo moral-religioso como era no direito natural, anteriormente.

O crime ou a infração penal é a ruptura com a lei, lei civil explicitamente estabelecida no interior de uma sociedade pelo lado legislativo do poder político. (...) Para que haja infração é preciso haver um poder político, uma lei e que essa lei tenha sido efetivamente formulada. Antes da lei existir não pode haver infração (Foucault, 1996, p. 80)

Outro princípio exposto diz respeito ao papel da lei penal. A lei, distante da "falta", deve representar uma utilidade para a sociedade. Deve definir ações que são nocivas ao conjunto social. O crime, assim, passou a ser objetivado como um ato que Rev. Polis e Psique, 2013; 3(2):132-150 promove um dano social, uma perturbação, um incômodo (Foucault, 1996). Esse deslocamento forja ressonâncias na produção de subjetividade, na medida em que inventa a figura do criminoso.

O criminoso, agora, é entendido enquanto o inimigo da paz social, o perturbador da ordem social. "O criminoso é um inimigo interno" (Foucault, 1996, p. 81). Redefinidos o papel e a função da lei, a noção de crime e a concepção de criminoso, qual seria, então, o papel da pena nesses termos apresentados? Para tal, Foucault responde:

\footnotetext{
A lei penal deve apenas permitir a reparação da perturbação causada à sociedade. A lei penal deve ser feita de tal maneira que o dano causado à sociedade seja apagado; se isso não for possível, é preciso que o dano não possa mais ser recomeçado pelo indivíduo em questão ou por outro. A lei penal deve reparar o mal ou impedir que males semelhantes possam ser cometidos contra o corpo social. (Foucault, 1996, p. 82)
}

Neste sentido, Foucault aponta quatro punições propostas pelos teóricos da época: a deportação, a vergonha pela publicação do crime cometido, o trabalho forçado e a pena de talião. Estas são as penas apresentadas pelos teóricos e legisladores da época. Porém, ao analisar o desenvolvimento e o funcionamento da penalidade pouco tempo depois, Foucault aponta para um acontecimento novo, uma forma de pu- 
nição pouco mencionada e discutida nos textos analisados: a pena de aprisionamento, de prisão. Para o autor:

Não só a prisão - pena que vai efetivamente se generalizar no século XIX - não estava prevista no programa do século XVIII, como também a legislação penal vai sofrer uma inflexão formidável com relação ao que estava estabelecido na teoria. (Foucault, 1996, p. 84)

Para Foucault (1996), a legislação penal vai se desviar do que os reformadores entendiam como utilidade social da pena para promover um ajustamento e uma correção, conforme a citação acima aponta. Foucault ressalta que a prisão é uma instituição disciplinar e não era alvo do debate dos penalistas na reforma da legislação penal. $\mathrm{O}$ inquietava estudar porque a prisão se torna a pena prioritária e porque ela também passou a funcionar no regime de internação dos corpos considerados desviantes da sociedade, também no plano das políticas de saúde, de assistência social e na educação.

Como exemplo deste deslocamento, o autor aponta o destaque crescente das "circunstâncias atenuantes", ou seja, a possibilidade de o juiz ou o júri modificar a penalidade aplicada ao indivíduo em julgamento, contradizendo o princípio de universalidade da lei enquanto representante dos interesses sociais. Outro apontamento do autor é um referido interesse penal em definir os atos em termos de risco/perigo; classificando-os como nocivos ou não à sociedade. Uma vez avaliado o ato como dano social, uma das punições é o afastamento da sociedade dos indivíduos classificados como perigosos da mesma. Afirma Foucault:

\footnotetext{
Toda a penalidade do século XIX passa a ser um controle, não tanto sobre se o que fizeram os indivíduos está em conformidade ou não com a lei, mas ao nível do que podem fazer, do que são capazes de fazer, do que estão sujeitos a fazer, do que estão na iminência de fazer. (Foucault,1996, p. 85)
}

Então, decidiu-se não mais aplicar a legislação penal sobre um ato apenas, mas juntamente retribuir o dano promovido pelo ato criminoso. Existe, a partir desta nova racionalidade penal, um esforço maior em criar uma noção de pena condizente com a de sujeito que teria motivações, uma biografia de desvios, o desenvolvimento de uma personalidade patológica. A virtualidade das ações é investigada e julgada. Pergunta-se se: pode este sujeito reincidir em sua atitude criminosa? Sua pena deve ser prolongada? Deve ser reduzida? Quem é esse sujeito que cometeu esse crime e que história ele teve?

Nota-se que, a partir da relação cada vez mais próxima entre norma e lei, entre prisão disciplinar e pena corretiva, aumenta-se o controle social preventivo por meio 
do que Foucault criticou como dispositivo de "periculosidade" e seus efeitos na produção do chamado sujeito-criminoso:

A noção de periculosidade significa que o indivíduo deve ser considerado pela sociedade ao nível de suas virtualidades e não ao nível de seus atos; não ao nível das infrações efetivas a uma lei efetiva, mas das virtualidades de comportamento que elas representam. (Foucault, 1996, p. 85)

Tais reformulações no fazer penal são concomitantes a uma série de práticas que passam a ofertar suporte disciplinar na gestão do risco-perigo. $\mathrm{O}$ controle penal, a vigilância e a correção dos indivíduos passam a ser diretrizes de uma rede, que passou a funcionar paralela ao sistema judiciário, como a polícia, a escola, o hospital, o asilo, etc. Para Foucault:

Toda essa rede de um poder que não é judiciário deve desempenhar uma das funções que a justiça se atribui neste momento: função não mais de punir as infrações dos indivíduos, mas de corrigir suas virtualidades. (Foucault, 1996, p.86)

Outro deslocamento apontado pelo autor diz respeito à produção da verdade e do fato penal em que o inquérito tende a ser articulado à tecnologia do exame. Lei e norma são articuladas com a relação entre o inquirir e o examinar em verdade Rev. Polis e Psique, 2013; 3(2):132-150 para produzir verdade e punir. As práticas de poder funcionam disciplinando os corpos, organizados os saberes, encaminhando e docilizando os corpos de acordo com as avaliações de peritos a respeito do campo de segurança e de saúde atrelado ao risco e ao perigo a ser gerido.

A partir das problematizações de Foucault acerca dos deslocamentos nos fazeres penais e disciplinares do século XVIII e XIX fica claro que alguns elementos levam o autor a qualificar esta sociedade (e sua forma jurídica) como sociedade disciplinar: não somente o inquérito, mas o acréscimo do exame; não mais investigar apenas a verdade de um ato cometido, mas também corrigir as virtualidades dos comportamentos dos indivíduos; não mais apenas a penalização do ato cometido, mas a correção ao nível dos perigos das condutas; não mais um poder irregular e descontínuo, mas a vigilância permanente e o controle intensivo.

Em Vigiar e Punir, Foucault (1999) destaca que o poder disciplinar funciona aumentando a produtividade dos corpos e os docilizando politicamente para que se tornem obedientes. A segregação pode ser disciplinar e punitiva ao mesmo tempo para corrigir e tratar seja na saúde e na segurança; todavia, os mecanismos de controle disciplinar não são apenas de isolamento na internação, podem ocorrer também em meio aberto nas ruas, na comunidade e na famí- 
lia. O modo de disciplinar difere de acordo com os objetivos e com as resistências ocorridas aos processos de adestramento.

No caso do uso de drogas legais e ilegais, é colocada a questão da disciplina no campo da saúde, da educação, da família, da segurança e do trabalho em termos de drogas que ajudam a fazer obedecer e de drogas que auxiliam a desobedecer. Então, a pena poder ser pela venda e pelo uso também, mas não se esgota neles, pois, as drogas podem ser parte do atendimento em saúde, do processo educativo, da punição, em práticas esportivas e do aumento de produtividade no trabalho, por exemplo.

Há pessoas que são internadas pelo uso de drogas e pessoas que são cuidadas com drogas, pessoas que são punidas com tratamentos; ou seja, há especialistas que prescrevem drogas legais para usuários de drogas ilegais, recomendam drogas para estudar e para dormir, para trabalhar e para controlar, para aliviar a dor e para anestesiar. Vivemos em uma sociedade que pune a venda e o uso de algumas drogas e fomenta e lucra com o sistema de repartição do lícito e do ilícito, disciplinando saberes e corpos também com a administração de outras drogas.

Trata-se de um paradoxo da disciplina e da prescrição de controles na saúde e na segurança, na economia e na política, na esfera do biopoder. Estamos falando de um processo de medicalização e de judicializaRev. Polis e Psique, 2013; 3(2):132-150 ção, em que a gerência dos corpos ocorre com o governo da vida, deslizando entre a segurança, a penalidade, a prevenção médico-psicológica educativa, a performance do corpo, a produção em avaliações e no trabalho, o tratamento de doenças e anestesia de sentimentos, a estimulação de ações e os prazeres.

Dessa maneira, se instala uma questão, de que drogas e que usuários são alvo das políticas de Estado? Por que a o uso de drogas acaba indo para o fundo frente ao legal e ao ilegal e em nome de quais interesses? Que indústrias entram em cena e quais não podem entrar no mercado das drogas? Por que se pode ficar anestesiado com psicotrópicos e em nome de quais jogos de poder, de saber e por quais processos de subjetivação? Ora, são muitas perguntas que nos auxiliam a problematizar e a analisar que há muitas linhas de força, nesse diagrama e, que tentar reduzi-lo apenas com a lógica explicativa causal e com a decisão política simplista de internação compulsória é um equívoco ou mesmo um paradoxo na sociedade atual, que afirma governar a vida e cuidar da saúde.

\section{Racismo de Estado e de Sociedade: medicalização securitária}

Michel Foucault pronunciou suas problematizações acerca do que é conhe- 
cido como "Racismo de Estado" em uma aula no dia 17 de Março de 1976. O conjunto de aulas apresentadas pelo pensador francês no ano de 1976 foi organizado no livro "Em Defesa da Sociedade". O autor inicia sua aula propondo um fechamento para o que foi trabalhado durante o ano, ou seja, a guerra das raças como um analisador político-estratégico. Sua conclusão é que o tema da raça não desapareceria, pelo contrário, seria retomado pelo racismo de Estado. Esse processo ocorreria por alguns motivos. Em primeiro lugar, Foucault cita a entrada da vida nos jogos de poder, ou:

[...] uma tomada de poder sobre o homem, enquanto ser vivo, uma espécie de estatização do biológico ou, pelo menos, uma inclinação que conduz ao que se poderia chamar de estatização do biológico. (Foucault, 2005, p. 286)

Para mostrar como isto se deu, Foucault retoma o modelo político da soberania e a dinâmica do poder sobre a vida nestes termos: o soberano é capaz de fazer morrer ou deixar viver. Aponta que o direito de vida e de morte exercia um papel fundamental, estando o súdito em uma condição de neutralidade, haja vista sua existência ou extinção estar vinculada ao poder exercido pelo soberano. Poder dissimétrico, diz Foucault, uma vez que o direito sobre a vida só era exercido a partir do direito sobre a mor- te, concluindo: "É essencialmente um direito de espada" (Foucault, 2005, p. 287).

Foucault, então, percebe um deslocamento, uma modificação no direito político a partir do século XIX que o leva a pensar em uma inversão dos termos apresentados: não mais fazer morrer e deixar viver. $\mathrm{O}$ direito político tornar-se-ia fazer viver e deixar morrer. Para dar luz à inflexão apresentada, o autor faz suas análises não problematizando a teoria política, "mas, antes, o nível dos mecanismos, das técnicas, das tecnologias de poder" (Foucault, 2005, p. 288). Desse modo, a biopolítica é a decisão de fazer viver alguns e deixar morrer outros.

No século XVII e XVIII, Foucault analisa técnicas e procedimentos de poder focados no corpo individual, que têm por efeito a produção de corpos dóceis: corpos potencializados em sua força de produção através de exercícios e treinamentos, organizados no tempo e no espaço, estudados em seus detalhes, sistematizados, vigiados, hierarquizados e classificados. Tal conjunto de técnicas é trabalhado pelo autor como tecnologia disciplinar do trabalho. No entanto, a partir da segunda metade do século XVIII, Foucault aponta para o surgimento de uma tecnologia de poder diferente da disciplinar e que não se destina a substituir esta, porém complementá-la, modificá-la parcialmente, somar-se com. Tecnologia esta que possui 
outro alvo: não mais o corpo singular, mas o corpo-espécie, o corpo enquanto massa global de uma sociedade, influenciada por processos da própria vida, como o nascimento, a morte, a doença, a produção, entre outros. Foucault, sobre essa transformação:

Depois da anátomo-política do corpo humano, instaurada no decorrer do século XVIII, vemos aparecer, no fim do mesmo século, algo que já não é uma anátomopolítica do corpo humano, mas que eu chamaria de uma "biopolítica" da espécie humana. (Foucault, 2005, p. 289)

Este conjunto de processos está relacionado à tentativa de dar conta de questões como os nascimentos, as mortes, a longevidade, as doenças, a partir de técnicas como a estatística, a demografia, o controle de natalidade, a medicina social, a higiene pública, entre outros, visando responder a problemas que afetam diretamente a capacidade e o custo de produção, seja pela redução da capacidade na força de trabalho, no tempo de trabalho ou pelo custo dispensado no tratamento das doenças. Preocupação esta também estendida aos idosos, aos acidentados, aos anormais. Estes processos tentarão aumentar a vida, controlar as eventualidades, os acidentes, as deficiências. Tentarão, por último, dar conta da relação da espécie humana com as condições do meio em que habitam, sejam estes naturais (pântanos, cli- ma, etc.) ou os meios produzidos pela própria vida humana: o problema das cidades.

Foucault vai apontar alguns elementos desta transformação que considera importante, a saber: o aparecimento de um corpo novo, a população, enquanto problema político e científico; uma modificação na natureza dos fenômenos: não mais fenômenos individuais, mas fenômenos coletivos e; a implantação de mecanismos que possuem funções diferentes dos mecanismos disciplinares: a biopolítica vai se ocupar de fenômenos globais e intervir no que existe de global nos fenômenos (estímulo na natalidade, aumentar a expectativa de vida da população) através de regulamentações, de estabelecimento de médias, de mecanismos de previdência, de otimização da vida (Foucault, 2005).

É valido relembrar que estes conjuntos de mecanismos disciplinares e reguladores não são excludentes, mas atuam articuladamente, uma vez que incidem em níveis diferentes do corpo: corpo-organismo (disciplina) e corpo-população (biopolítica). E é justamente este ponto de articulação entre estas tecnologias de poder que Foucault atribui à norma. A norma é o que possibilita um corpo a ser disciplinado e a população a ser regulamentada. É a partir desta articulação que é possível pensar, para o autor, uma definição mais exata de sociedade de normalização: 
A sociedade de normalização é uma sociedade em que se cruzam, conforme uma articulação ortogonal, a norma da disciplina e a norma da regulamentação. Dizer que o poder, no século XIX, tomou posse da vida, dizer pelo menos que o poder, no século XIX, incumbiu-se da vida. (Foucault, 2005, p. 302)

Foucault, após apresentar como esta transformação no direito político se passou e apresentar caminhos possíveis no fazer viver, problematiza o outro lado da moeda: o deixar morrer. Afinal, não seria um paradoxo esta relação? Como um poder cujo objetivo é potencializar a vida pode permitir o seu avesso, o ponto de fuga deste poder, o seu limite, o ponto onde o poder não pode ser exercido, a saber, a morte? Eis aí a intervenção do racismo de Estado e sociedade, mecanismo que só fora possível pela emergência do biopoder. Sobre o racismo, Foucault aponta:

Com efeito, que é o racismo? É, primeiro, o meio de introduzir afinal, nesse domínio da vida de que o poder se incumbiu, um corte: o corte entre o que deve viver e o que deve morrer. (...) Em resumo, de estabelecer uma cesura que será do tipo biológico no interior de um domínio considerado como sendo precisamente um domínio biológico. (Foucault, 2005, p. 304)

O racismo de Estado e de sociedade encarrega-se de algumas funções nos Esta- dos modernos, atuando pela via da biologização cientificista. Em primeiro lugar ele tem por função fragmentar a população em raças, grupos, alguns melhores e outros inferiores; em segundo lugar, possui uma função legitimadora, de aceitabilidade do extermínio do outro, a partir da lógica de que, para que eu-espécie possa viver, é necessário que o outro-espécie-inferior não sobreviva, é necessário que os perigos externos e internos sejam eliminados:

\begin{abstract}
A morte do outro não é simplesmente a minha vida, na medida em que seria minha segurança pessoal; a morte do outro, a morte da raça ruim, da raça inferior (ou do degenerado, ou do anormal), é o que vai deixar a vida em geral mais sadia; mais sadia e mais pura (Foucault, 2005, p. 305)
\end{abstract}

Neste sentido, o autor afirma: "A raça, o racismo, é a condição de aceitabilidade de tirar a vida numa sociedade de normalização" (Foucault, 2005, p. 306). Para o Estado poder matar ou deixar morrer é necessário que acione o racismo. Foucault alerta para as mortes possíveis nos Estados modernos nas sociedades de normalização, onde funciona o biopoder em que está em jogo não apenas tirar a vida diretamente, mas expor à morte, multiplicar o risco à morte para alguns grupos, matar politicamente, excluir, rejeitar, expulsar, etc. 
Outro elemento a ser analisado no aparecimento do racismo de Estado é o destaque dado à teoria biológica evolucionista do século XIX. O evolucionismo proporcionou uma possibilidade de pensar as colonizações, as guerras, a criminalidade, a loucura, a doença mental, as diferenças de classes, etc. A relação do evolucionismo com o racismo de Estado pode ser pensado a partir da relação entre ciência e Estado, conhecimento científico "neutro" e legitimidade de ações, discursos e produção de verdades. Ainda sobre o racismo, Foucault pensa a constituição e a gestão da criminalidade e da loucura nos Estados que operam o biopoder:

Se a criminalidade foi pensada em termos de racismo foi igualmente a partir do momento em que era preciso tornar possível, num mecanismo de biopoder, a condenação à morte de um criminoso ou seu isolamento. Mesma coisa com a loucura, mesma coisa com as anomalias diversas. (Foucault, 2005, p. 308)

É através do racismo de Estado e de sociedade que é possível legitimar a morte de um grupo, de uma raça, ou mesmo de um criminoso, de um louco. É operando o contínuo biológico do duo corpo-organismo e corpo-espécie que emerge e constitui-se o racismo. Racismo este sustentado, muitas das vezes, pelo arcabouço teórico da medi- cina, da psiquiatria, da psicologia, entre outros.

Nesse aspecto, podemos pensar que internar e internar compulsoriamente e em lugares em condições precárias pessoas pelo uso de drogas bem como aprisionar os que comercializam drogas classificadas como ilícitas são práticas que entrecruzam: disciplina policial-penal com biopolítica racista, na vertente correção médico-psicológica securitária. A medicalização autoritária é mais presente na internação do que qualquer lógica terapêutica. $\mathrm{Na}$ pena de prisão para venda de drogas, o pequeno tráfico e sua ponta se tornaram crimes intensamente penalizados com recrudescimento cada vez maior. Nas duas situações, medicalização e jurisdicionalização são articuladas por meio do dispositivo racista do biopoder.

\section{Projetos de Lei como práticas sociais medicalizadas e jurisdicionalizadas}

Os Projetos de Lei aqui analisados foram selecionados seguindo o critério da atualidade. São projetos que sugerem alterações no plano da lei sobre drogas no Brasil. O Projeto de Lei n 3.450 de 2012, de autoria do Sr. Alfredo Kaefer, pretende autorizar o poder público a internar compulsoriamente crianças, adolescentes e adultos em situação de risco em função do uso de drogas. O Projeto de Lei no 4.871 de 2012, 
de autoria do Sr. Francisco Escórcio, pretende acrescentar à Lei $n^{\circ} 11.343$ de 2006: Lei de Drogas, especificamente em seu vigésimo oitavo artigo, encaminhamento (coercitivo ou não) à investigação pericial sobre o objeto dependência química para que o juiz possa, de acordo com os resultados da perícia técnica, determinar ao infrator a pena de internamento compulsório.

A primeira problematização que gostaríamos de interrogar é o fato de que os Projetos de Lei estar organizados e sustentados pelo saber-poder das ciências humanas e da saúde. As ciências "psi” aparecem, historicamente, enquanto discursos legitimadores da gestão das condutas dos usuários de drogas no Brasil. Vê-se, assim, dois movimentos que devem ser destacados: a construção dos "problemas sociais" e a "resolução" destes problemas criados. Para ilustrar:

Art. $1^{\circ}$. Esta lei autoriza o Poder Público a internar, compulsoriamente, as crianças, os adolescentes e adultos usuários de drogas e em situação de risco, para tratamento médico especializado. (...) $\S 1^{\circ}$ A Comissão referida no caput será composta de três membros com notória experiência acerca da dependência química, sendo pelo menos um deles médico, nos termos regulamentares. (Projeto de Lei $\mathrm{n}^{\circ} 3.450$ de 2012, de autoria do Sr. Alfredo Kaefer)

Art. 28-A. Em havendo indícios, pela natureza da substância apreendida e pelo comportamento do infrator, que ele esteja acometido de dependência química grave, o juiz poderá, de ofício ou a requerimento da autoridade policial ou do Ministério Público, determinar que seja o próprio submetido, coercitivamente se necessário, a exame pericial. $\S 1{ }^{\circ}$. Se confirmada a dependência, o juiz determinará a internação compulsória do infrator em instituição que atenda usuários ou dependentes de drogas, pelo prazo determinado no laudo pericial. (Projeto de Lei $n^{\circ} 4.871$ de 2012, de autoria do Sr. Francisco Escórcio)

Passetti (1991) ajuda-nos a pensar a relação ciência-Estado e a construção dos "problemas sociais", força importante no avanço da administração do cotidiano pelo Estado:

Assim, a ciência aparece construindo, esquadrinhando, propondo e definindo os problemas sociais em áreas específicas, através de estudos interdisciplinares, com o objetivo de conter e administrar soluções possíveis. Batalhões de cientistas dos mais diversos ramos do saber, diretamente vinculados a órgãos criados, recriados ou recém-criados, sob as variadas concepções de mundo, se aninham ou se vinculam ao Estado para, dotados de verbas, encontrarem as soluções plausíveis. (Passetti, 1991, p. 15)

Foucault (2011) problematiza a função dos discursos de verdade na sociedade disciplinar enquanto suporte para o sistema penal que se instaura: 
Penso ainda na maneira como um conjunto tão prescritivo quanto o sistema penal procurou seus suportes ou sua justificação, primeiro, é certo, em uma teoria do direito, depois, a partir do século XIX, em um saber sociológico, psicológico, médico, psiquiátrico: como se a própria palavra da lei não pudesse mais ser autorizada, em nossa sociedade, senão por um discurso de verdade. (Foucault, 2011, p.18-19)

Assim, nos Projetos de Lei aqui analisados, observamos uma atualização da relação Estado-ciência na construção e gestão do problema da droga no Brasil. As ciências da saúde sustentam e reafirmam um sistema de disciplinamento pela correção das condutas desviantes (uso de drogas). Correção esta que também é campo destes saberes, uma vez que a internação compulsória é a medida sugerida, em ambos, para tratamento e ajustamento dos indivíduos.

Outra força que atua na gestão dos comportamentos dos usuários de drogas no Brasil é a demonização da droga, do traficante e do usuário. O problema das drogas vai ser encarado como um fator que impede o desenvolvimento do país, situando nos sujeitos envolvidos nesta trama a noção de "inimigo a ser combatido", seja pela via da criminalização-penalização (observamos cotidianamente programas de televisão, jornais e afins clamando por maiores e "melhores" penas para o Rev. Polis e Psique, 2013; 3(2):132-150 tráfico de drogas) ou pela via da correção-internação, modelo de tratamento imposto ao usuário enquanto penalidade para o ato de se drogar.

\begin{abstract}
Um dos mais graves problemas que assolam o nosso país é o flagelo das drogas e, mais recentemente, mas de forma avassaladora, do "crack", que se revelou uma substância com poder de destruição que poderíamos classificar como devastador. (Projeto de Lei $n^{\circ} 4.871$ de 2012, de autoria do Sr. Francisco Escórcio)
\end{abstract}

Quando Estado e sociedade situam nas drogas, em especial, nas ilícitas e naquele que delas faz uso como um dos mais graves problemas que assola o país; podemos perceber o quanto o racismo está presente. Encontramos um corte possível dentro da população: aqueles que usam e produzem problemas considerados indesejáveis à nação e aqueles que não usam, portanto, sofrem com as consequências dos atos dos primeiros. Retomando as análises de Foucault, temos:

A morte do outro não é simplesmente a minha vida, na medida em que seria minha segurança pessoal; a morte do outro, a morte da raça ruim, da raça inferior (ou do degenerado, ou do anormal), é o que vai deixar a vida em geral mais sadia; mais sadia e mais pura. (Foucault, 2005, p. 305). 
A análise de Foucault sobre as virtualidades dos atos também pode ser evidenciada nas justificativas dos Projetos de Lei. Observamos uma racionalidade que situa o usuário de drogas enquanto um perigo para si e para a sociedade, uma vez que todo uso de drogas (ilícitas) vai ser entendido como danoso. O usuário é produzido enquanto sujeito perigoso, que deve ter suas virtualidades corrigidas, deve retornar à norma, em função de apresentar um perigo potencial. Deve ser corrigido ao nível de suas virtualidades no presente, em busca de uma normalização no futuro.

Ora, receber "socorro em quaisquer circunstâncias", inclui, evidentemente, a intervenção indispensável do Poder Público num momento em que o jovem é encontrado se drogando, situação que coloca em risco sua vida. (Projeto de Lei $n^{\circ} 3.450$ de 2012, de autoria do Sr. Alfredo Kaefer)

Por último, a racionalidade também é produzida a partir da noção médico-psicológica de que o usuário de drogas, em situação de abstinência (ausência de droga), pode comprometer sua saúde e a saúde dos outros quando procura retroalimentar sua suposta ação, nomeada de maneira patologizante como compulsão. Evidenciamos estes elementos na citação, abaixo:

Essa verdadeira legião de desassistidos, inclusive, vem contribuindo para o aumento sensível da criminalidade, visto que muitos dependentes buscam no crime as condições financeiras para o sustento de seu vício. (Projeto de Lei $\mathrm{n}^{\circ} 4.871$ de 2012, de autoria do Sr. Francisco Escórcio)

\section{Conclusões provisórias}

$\mathrm{Na}$ análise dos Projetos de Lei, podemos perceber articulações possíveis entre a gestão das condutas dos usuários de drogas, a dinâmica das virtualidades dos comportamentos associados ao uso (e seu tratamento) e o racismo de Estado e sociedade, enquanto produtor de segregações, de cortes dentro da população, legitimadores do "deixar morrer" (morte política, exclusão) característicos do que identificamos enquanto sociedade de normalização.

O usuário vai sendo produzido enquanto sujeito potencialmente perigoso para si e para os outros. Logo, em nome de sua própria vida (capturada enquanto integridade "física e mental") e em nome da sobrevivência do corpo-espécie, legitimam-se políticas de exclusão, de internamento em massa.

O biopoder atualiza-se na dinâmica das forças do "problema" droga: disciplinando o corpo-organismo, pela vigilância ao excesso (exame pericial, exames de sangue) e a obrigação da reforma, na punição pelo tratamento enquanto penalidade para o uso de drogas não autorizadas pelo Estado 
e; regulamentando o corpo-espécie, o corpo da população, governando, em nome da sobrevivência da ordem social, o cotidiano deixar morrer voltado para os grupos subjetivados enquanto perigos internos: os matáveis.

Tais acontecimentos têm sido discutidos pela grande mídia nacional sensacionalista, por grupos de parlamentares e partidos com fins eleitoreiros e com interesses econômicos. O sofrimento de familiares de usuários tem sido capturado em uma agenda de retorno da internação com características manicomiais, defendida por profissionais e parlamentares que visam comercializar a saúde e segregar os refugos produzidos pela sociedade contemporânea.

Em resistência a esse processo, foi criada a Frente Nacional Drogas e Direitos Humanos, em 2011 como uma iniciativa dos conselhos de profissão no Brasil, como Conselho Federal de Psicologia, Conselho Federal de Serviço Social e a Ordem dos Advogados do Brasil, por movimentos sociais: Movimento de Luta Antimanicomial, Movimento Nacional da População em Situação de Rua, Marcha da Maconha, pelas mídias alternativas de maneira mais crítica, Associações de pesquisadores e entidades de direitos humanos, entre outros.

Rev. Polis e Psique, 2013; 3(2):132-150

\section{Referências}

Foucault, Michel. (1979a) “A política de saúde no século XVIII". Microfísica do poder. Rio de Janeiro: Graal.

Foucault, Michel (1979a) "Nietzsche, a genealogia e a história". In: Microfísica do poder. Rio de Janeiro: Graal.

Foucault, Michel. (2011). A ordem do discurso. São Paulo: Edições Loyola. Foucault, Michel. (1984). Microfísica do poder. 25. ed. Rio de Janeiro: Graal.

Foucault, Michel. (1999). Vigiar e punir: a história da violência nas prisões. Petrópolis/RJ: Vozes.

Foucault, Michel (1996). A verdade e as formas jurídicas. Rio de Janeiro: Nau.

Foucault, Michel. (2005). Em defesa da sociedade. São Paulo, RJ: Martins Fontes.

Lemos, Flávia et al. (2010).“A análise documental como instrumento estratégico para Michel Foucault". In: Pimentel, A.; Rodrigues, M.; Nicolau, R. F., Lemos, F. C. S. (orgs.) Itinerários de pesquisa em psicologia. Belém: Amazônia.

Passetti, Edson. (1991). Das fumeries ao narcotráfico. São Paulo: EDUC.

Pol-Droit, Roger. (2006). Michel Foucault: Entrevistas. São Paulo: Graal. 
Artur Barbedo do Nascimento Couto:

Psicólogo. Mestrando do Programa de Pós-

-Graduação em Psicologia da Universidade Federal do Pará (UFPA). Conselheiro do Conselho Regional de Psicologia da $10^{\mathrm{a}}$ Região (Pará e Amapá). Membro da Frente Paraense sobre Drogas e Direitos Humanos

E: mail: arturcoutopsi@yahoo.com.br

Flávia Cristina Silveira Lemos: Profa. adj. III em psicologia social/UFPA. Psicóloga/ UNESP, Mestre em psicologia e sociedade/
UNESP, Doutora em história/UNESP, Bolsista de produtividade em pesquisa CNPQ

E: mail: flaviacristinasilveiralemos@ yahoo.com.br

Mariane Batista Bittencourt Couto: Pedagoga/UEPA. Psicóloga/UFPA. Integrante da Frente Paraense sobre Drogas e Direitos Humanos

E: mail: maribatista07@hotmail.com

Recebido em: 16/11/2013 - Aceito em: 17/03/2014 